\title{
قيمة الإنسان
}

\author{
لمؤلف: عبد المجيد النجار \\ الناشر: دار الزيتونة للنشر - الرباط - المغرب \\ الطبعة الثانية: 1417هـ/1996م، (103ص)
}

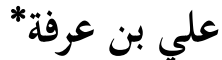

\section{تمهيد}

"الإنسان في العقيدة الإسلامية"، ذلك هو المشروع الجميد للدكتور عبد المجيد النجار، الذي يطمح من

خلاله إلى تأسيس فرع عَقَديٍّ خاص بالإنسان، يسميه "علم الإنسان الإسلامي" ويقصد بهذا الأخير "بناء تصور إسلامي للإنسان مستخلص من التحديدات التي جاءت بها العقيدة الإسلامية في نصوص القرآن الكريم والحديث النبوي الشريف مبينةً حقيقة الإنسان ووظيفته الوجودية وغايته". 1 وفي إطار هذا المشروع، يأتي كتاب قيمة الإنسان، بوصفه حلقة ثابتة في سلسلة ذات حلقات خمس، ابتدأها بكتابه القيم "مبدأ الإنسان، وإذا كان الإنسان في العقيدة الإسلامية يتساوى مع سائر الموجودات من جهة وضعه الوجودي، إلاّ أنّه يشترك معها في القصور الذاتي الذي صارت من خلاله معلولة للخالق سبحانه وتعالى، فإنه من حيث وضعه القيمي يتميز منها تميزاً نوعياً، مما يجعله يستقل بسلم قيمي يتجاوز ذلك الذي تندرج ضمنه سائر

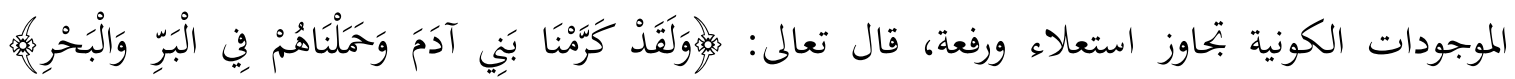
(الإسراء: 70)، إن التكريم في هذه الآية نراه شاملاً للإنسان بمقتضى مطلق الإنسانية فيه، ومتجلياً في تسخير البر والبحر -الكون- لما فيه خيره، وهما المظهران الأساسيان اللذان يشكلان الموقف العقدي في تقويم الإنسان، ويتناولما المؤلف بالشرح في فصلين يستقل أولما ببيان القيمة الذاتية للإنسان، في حين

$$
\begin{aligned}
& \text { * بكالوريوس في الفلسفة - جامعة نواكشوط - موريتانيا. } \\
& 1
\end{aligned}
$$


يبحث في الثاني منزلته في الكون، وفي ختام كل فصل يقف على الأثر التربوي الذي يخلفه الإيمان بالموقف العقدي على المستوى الفردي والاجتماعي.

\section{1 - القيمة الذاتية للإنسان}

يجظى الإنسان في التصور الإسلامي وبمقتضى مطلق الإنسانية فيه بتكريم عظيم، فقد حُصّ دون سائر

الموجودات بشرفية الخلق، أضفتها عليه العناية الإلهية التي بتلت في خلقه بيد الله سبحانه وتعالى، ومن المعلوم كما يقول الرازي: "إنَّ السلطان العظيم لا يقدم على شيء بيده إلاًّ إذا كانت غاية عنايته مصروفة إلى ذلك العمل". (ص14) كما أنه قد أكرمه بأنه نفخ فيه من روحه، وجعله على صورته، وأعده لخلافته في الأرض. ولقد حاز الإنسان فضلاً عن ذلك على أحسن التقويم بدليل قوله تعالى:

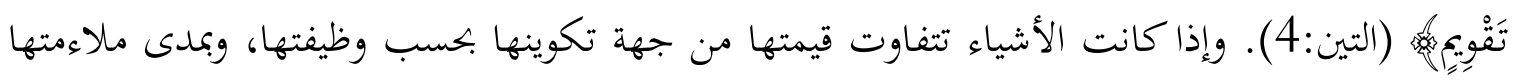
للقيام بتلك الوظيفة، فإن الإنسان قد خلق لأعظم وظيفة في هذا الكون، وهي وظيفة الخلافة عن الله في الأرض. أما حين نتأمل بنيته المادية والمعنوية، فإننا نقف على انسجامها مع ما عُهََِ إليه من مهمة ووظيفة في الحياة، فضلاً عن امتداد قامته إلى الأعلى، وتركز وسائل الإدراك في طرفها الفوقي، مما يهيئه للإشراف على الظرف المكاني المحيط به على أبعاد كبيرة وجهات مختلفة، فإنه في بنيته المعنوية قد خُصِّ بالعقل، الذي يستطيع من خلاله استيعاب ما هو غائب من الحقائق، مما يحقق له السيطرة على البيئة الكونية بامتلاك قوانينها. ولقد شاءت الإرادة الإلهية أن يختار الإنسان من بين سائر الموجودات، ليكون مكلفاً بحمل الأمانة، ومن المعلوم أن التكليف لا يقوم إلاعلى الحرية مما يشير إلى تملك الإنسان لمصيره بيده، وفي ذلك ارتفاع بقيمة هذا الكائن عن بقية الكائنات التي لا تملك تحديد مصيرها، وحينما نتأمل جوهر هذا التكليف الإلهي، نراه ينزع بابتحاه مغالبة عوامل السقوط عند الإنسان، ونصرة عوامل الترقي والتسامي، مما يتقدم به خطوات نهو اكتمال معاني الإنسانية فيه، وتكل منة إلهية بتعل من التكليف طريقاً إلى مقام الإنسانية الحق، هذا المقام الذي ينتهي إلى عبادة الله حق العبادة، ولا عزة للإنسان ولا رفعة لشأنه إلا في ظل العبودية لله والخضوع له. ويشرح المؤلف هذا المعنى بالنظر في مظاهر العزة في مطلق العبادة لله، ثم في تبلياها على مستوى العبادات التي ضبطتها الشريعة الإسلامية. ففيما يتعلق بعبادة الله بإطلاق، فإن هذه الأخيرة بتعل 
من الله سبحانه وتعالى هو الهدف النهائي لكل مناشط الإنسان، ومن الطبيعي أن تثمر عظمة الأهداف شعوراً بعظمة النفس، إذ أن الأهداف القريبة من دون الله لا تخلف في النفس إلا مشاعر الإحباط واليأس

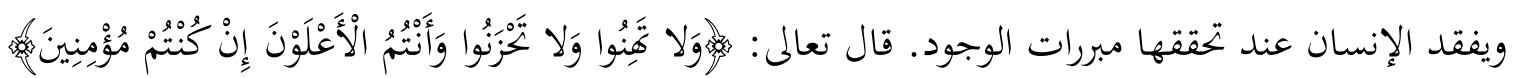

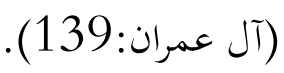

أما فيما يخص الضوابط الشرعية التي يتحقق من خلالما تكريم الإنسان واقعياً، فإن المؤلف يحيلنا إلى تلك الأحكام المتعلقة بتعامل الإنسان مع نفسه والكون والآخرين. فالشريعة الإسلامية فرضت أشكالاً من العبادات تحفظ كرامة الذات الإنسانية، وترتفع بها عن مستوى عبادة الشهوات. كما حرمت الاعتداء على الإنسانية والحط من قيمتها من خلال تحريم كل أشكال التهلكة التي يمكن أن يلقي الإنسان بنفسه فيها.

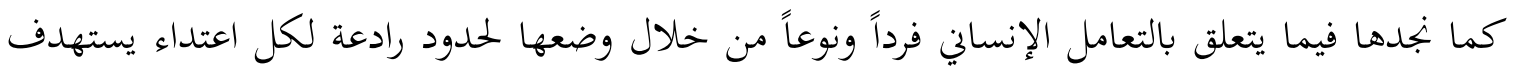
هذا الكيان، كما نراها على المستوى السياسي ترفض الانحراف عن القانون الإلهي الضامن لكرامة الإنسان ورفعته، وبتعل من الثورة انتصار للحرية ورفضاً لكل أشكال الظلم والبغي واجباً دينياً.

وبعد كل ما سبق ذكره من مظاهر التكريم للإنسان، يتساءل المؤلف عن معنى التكريم والرفعة لهذا الكائن إذا ما تصورنا أن مصيره النهائي بعد الموت مآله إلى العدم. وهنا يبرز التفضل الإلهي الذي أكرم

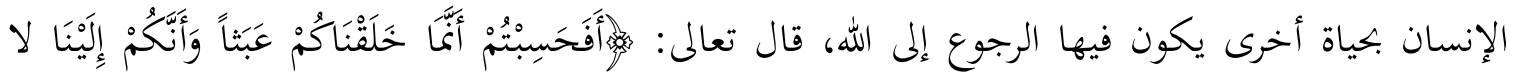

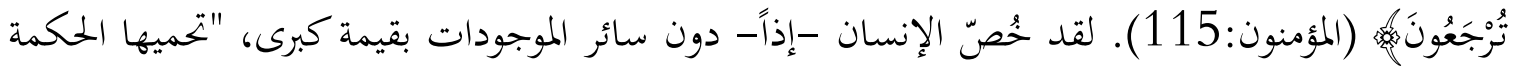
الإلهية الخالصة من كل عبث متوهم، وإنما مصدر تلك القيمة ومظهر تلك الحكمة، ما رتب على هذه الحياة من حياة أخرى يكون فيها الرجوع إلى الله للحساب". (ص 50). وإذا كان لكل معتقد آثاره، فإن لعقيدة تكريم الإنسان آثارها في نفس هذا الأخير، إذ هي تثمر لديه إحساساً قوياً بوجوده، وثقة في ذاته، مما يدفعه إلى الفعل في الكون فعلاً عميق الأثر، لأنه يتعلق بغاية بعيدة هي الله سبحانه وتعالى. ومن البيّن أن هذه الآثار تختلف عن مشاعر الإحباط واليأس التي تمثل النتيجة المنطقية لتصور الوجود الذي يقوم على الصدقة العمياء، ولحياة خالية من الهدف، حصراً لكيان الإنسان في بُعد مادي مظلم. 
ينطلق المؤلف في تقويمه لعلاقة الإنسان بالكون، من الأساس العقدي، لشرح الوجود والغاية من الوجود الإنساني في العقيدة الإسلامية، ومن المعلوم أن تصور الوجود في هذه الأخيرة يقوم على ثنائية الخالق والمخلوق، والوجود الإنساني إنما يهدف إلى تحقيق خلافة الله في الأرض فكيف تتحدد منزلة الإنسان في الكون تبعاً لذلك؟

يرى المؤلف أن منزلة الإنسان في الكون تتحدد في المحاور الثلاثة الآتية:

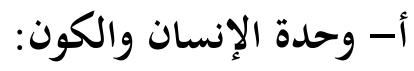

يعبر المؤلف عن الترابط الوجودي بين الإنسان والكون بمفهوم "وحدة الوجود"، والمقصود به ذلك الاشتراك بين الإنسان والكون في عملية الخلق الإلهي من عدم والرجعة إليه بعد انقضاء عالم الشهادة،

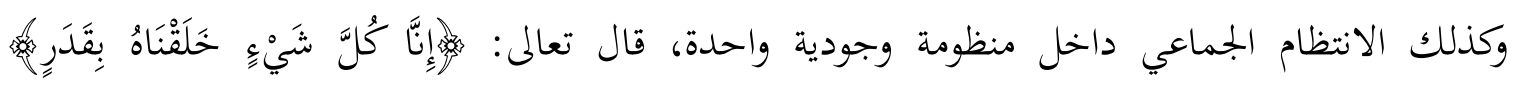
(القمر:49). كما أن هناك "وحدة في التكوين" تجمع بينهما، إذ الإنسان كما ذكرَت الآيات القرآنية إنما

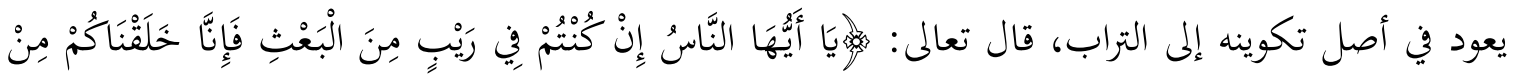
تُرَابِيُم. (الحج:5). والمظهر الأخير من مظاهر الوحدة بين الإنسان والكون هو ذلك القانون الموحد الذي ينتظمهما في النشأة والصيرورة، وهو ما يعبر عنه المؤلف "بوحدة النظام".

\section{ب - استعلاء الإنسان على الكون:}

يرى المؤلف أن للإنسان استعلاءً وجودياً على الكون، والمقصود بذلك أن الإنسان "منذ وجوده أصبح كقطب التّحى في تراجع الموجودات إليه تراجع تقدير وخدمة"، (ص73)، ولقد ورد في قصة الخلق ما يشير إلى ذلك على "استعلاء تكويني" تمثل في استجماعه لما تفرق من عناصر التكوين في الكون، فاستجماع الإنسان لعنصري المادة والروح في تكوينه، يؤهله للارتقاء إلى مرتبة كيفية، يستعلي بها على بقية الموجودات، فهو كما يقول الأصبهاني: "من حيث إنه صغّر شكله وجمع فيه قواه، كالمختصر من العالم، فإن المختصر من الكتاب هو الذي قل لفظه واستوف معناه، والإنسان هكذا هو إذا اعتبر بالعالم. (ص 73). كما تفرد 
الإنسان بالقدرة على استجماع صورة الكون في ذهنه تمثلاً واستيعاباً، وذلك ما يعبر عنه المؤلف بـ "استعلاء

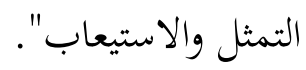

\section{ج - تسخير الكون للإنسان:}

لقد وردت في القرآن الكريم آيات عديدة تفصّل مظاهر تسخير الكون للإنسان، سواء لأجل وجود هذا الأخير بانبنائه على ما يناسب الكيان الإنساني، أو لاستمرار حياته من خلال تيسير سبل الحصول على لى

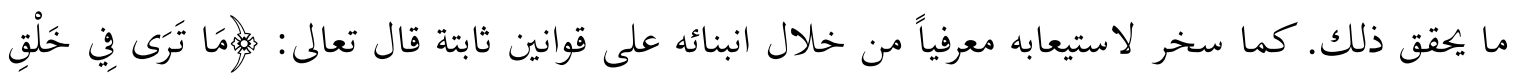

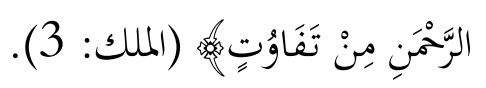

ولقد حاول المؤلف أن يتتبع الآثار التي يخلفها هذا التصور لعلاقة الإنسان بالكون، إذ أن تعامل الإنسان مع الطبيعة كان دائماً محكوماً بالتصورات التي يحملها الإنسان عن علاقته بها، فاعتقاد "وحدة الوجود" مثلاً، ينفي مشاعر الخوف والعداء ليرسخ مشاعر القرى التي هي "الشرط الأول لصنع مناخ نفسي تستعد فيه نفس الإنسان للإقبال على الكون والانفتاح عليه والتعامل معله بتلقائية ويسر" (ص:84)، وذلك على خلاف مفاهيم الصراع التي تقوم على روح عدوانية تجاه الكون وتترجم ألفاظها مثل "غزو الفضاء". كما أن الشعور بالاستعلاء يمثل دافع الفعالية من أجل تحقيق تلك الرفعة واقعياً باستثمار الكون وتعميره، والتعاليم الإسلامية إذ تشعر الإنسان بالرفعة والاستعلاء، فإنها تحميه من مشاعر التعاظم المفرط، من خلال عبوديته لله تعالى.

\section{3- ملاحظات تقويمية}

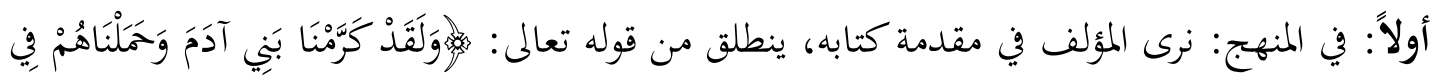

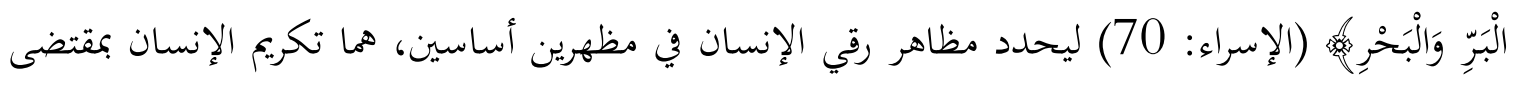
مطلق الإنسانية فيه، وتسخير البر والبحر -الكون- لما فيها خيره، وانطلاقاً من ذلك، يتناول الموضوع في فصلين يستقل أولما ببيان القيمة الذاتية للإنسان، ويستأثر الثاني بمنزلة الإنسان في الكون، لتأكيد العلاقة التسخيرية بين الإنسان وهذا الأخير التي يصير بمقتضاها الإنسان أعلى شأناً مما سخر له. وفي خاتمة كل 
فصل يتتبع الكتاب الآثار الإيجابية للتصور الإسلامي على المستوى النفسي والاجتماعي، مع مقارنتها بآثار غيره من التصورات. ونسسب أن هذه المنهجية موفقة لتناول الموضوع لانطلاقها أولاً من نصوص الوحي لتحديد حقيقة الموضوع كلياً، وبناءً على ذلك تتحدد فصول الكتاب التي تتناول الموضوع تفصيلياً، فتساهم في إبراز آثارها النفسية والاجتماعية نتيجة لمقدمة سابقة. ثانياً: يؤكد المؤلف في بداية كتابه أن الإنسان يستقل وحده بسلم قيمي يتجاوز السلم الذي تندرج ضمنه سائر الموجودات، وقد لا نختلف مع هذا الرأي لولا أن كلام الكاتب يوحي باستخلاص هذا المعنى من نصوص الوحي حين يتحدث عنه قائلاً: "وهذا المعنى يؤكده القرآن الكريم فيما خصّ به الإنسان من بيان لخلقه خلقاً ابتدائياً مستقلاً، وهو ما لم يخص به أي كائن من الكائنات الأخرى، بل جاء الحديث عنها جميعاً في صعيد واحد، وهو ما يبدو جلياً في فاتحة الوحي، إذ يقول تعالى في أول ما نزل من القرآن الكريم:

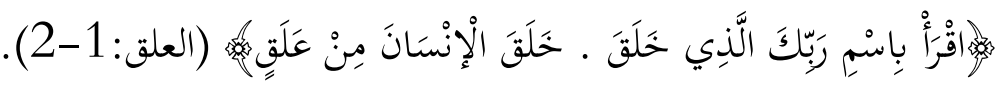

ففيما يتعلق بالخلق الابتدائي المستقل، ذكر المؤلف في كتابه مبدأ الإنسان أن هذا الموقف لا يرتقي إلى مرتبة اليقين، وإنما هو يتبناه بمقتضى غلبة الظن، وبالتالي فإننا لا نستطيع الجزم بتأكيد القرآن استقلال الإنسان بسلم قيمي بناءً على هذا الموقف. أما الآية المذكورة سابقاً، فنحسب أها تنبه إلى تأمل عملية الخلق

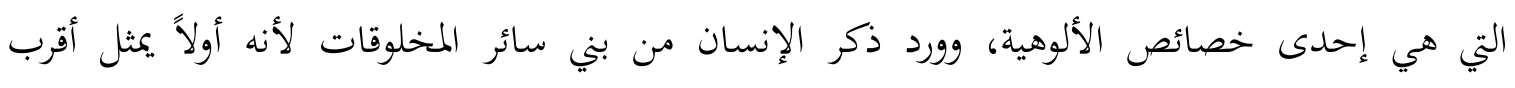

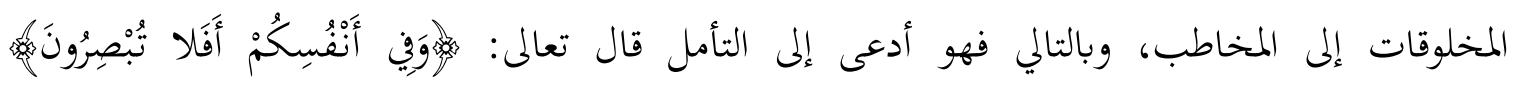
(الذريات:21). وثانياً: لأنه من بين سائر الموجودات تلحظ فيه معجزة الخلق جَليّة، لانفراده بمكرمة العقل، في حين أن بقية المخلوقات قد يختلط فيها على الإنسان الخلق بالصنع أو التحول، فعملية خلق الإنسان من العلق، هي عملية إضافة وابتكار لعنصر الروح المفقود في العلق والمتجسد في الإنسان، والذي يشير بجلاء إلى عملية الخلق وقدرة الخالق. فالإنسان هو بالتأكيد في منزلة قيمية أعلى بالنسبة لسائر الموجودات وقد لا يندرج مع سائر الموجودات ضمن سلم قيمي واحد، كما يذهب إلى ذلك المؤلف.

غير أننا نحسب أن هذا المعنى يتجاوز مدلول الآية المذكورة، ولا نعتقد أن القرآن الكريم يؤكده أو ينفيه، وإنما نتبناه كتصور يعتمد ملاحظة انفراد الإنسان باستجماع عنصري المادة والروح في تكوينه، مع تحمله 
لأمانة التكليف، ومسؤولية الحرية، مما يرشحه للانفراد بسلم قيمي يتجاوز ذلك الذي تندرج ضمنه سائر الموجودات الكونية.

ثالثاً: تتبع المؤلف في الفصل الأول مظاهر "العزة في التعبد"، بعد أن عرف العبادة بأها: التوجه المستمر نخو الله بالحضضوع والمذلة. ولقد حاول تجاوز ما قد يبدو من التناقض بين المذلة والعزة في العبادة، من خلال التركيز على مشاعر العظمة التي تغمر النفس حين تتوجه إلى هدف عظيم متمثلاً في الله سبحانه وتعالى، كما استشهد بتعريف محمد إقبال للصلاة بأهما "فعل فريد من أفعال الاستكشاف، تؤكد به الذات الباحثة وجودها في نفس اللحظة التي تنكر فيها ذاتا". غير أن تأكيد المشاعر التي تغمر النفس لحل التناقض بين العزة والذلة التي يمتويهما مفهوم العبادة، لا يككنا من تحقيق القناعة العقلية التي هي هدف علم الكلام، والذي يريد "مشروع الإنسان في العقيدة الإسلامية" أن يكون أحد فروعه المستقلة. ونخسب أن الدكتور الترابي كان أكثر توفيقاً في تحاوز هذا الإشكال الذي عرضه بصيغة تناقض حاصل في العبادة بين مفهومي الحرية والعبودية، فالحرية كما يقول: "هي قدر الإنسان الذي تميز عن كل مخلوق سواه، فسجد لله طوعاً، إذ لم يجعل الله في تركيبه ما يجبره على الإيمان، ولا سمح له بأن يجبر غيره على الإيمان، إن الحرية ليست غاية، بل وسيلة لعبادة الله، وإن هذه العبودية لا تثير شعوراً بالمجانبة لأن المؤمن يعبد الله بدافع الخمبة والإجلال، واستشعار النعمة الدافعة إلى الشكر الأمر الذي يجعل الحرية الوسيلة والثمرة لعبادة الله". 2 فعبودية الله إذا هي اختيار حُرٌّ بدافع المحبة والشكر وهما لا يمكن أن يعبرا بأي حال عما يناقض الحرية والعزة.

رابعاً: ذكر المؤلف خلال حديثه عن الآثار التي يخلفها الإيمان بعقيدة تكريم الإنسان أن أهم عوامل إعاقة الأمة الإسلامية عن التحضر يتمثل في شعورها بالمغلوبية والدونية إزاء الآخرين من أهل الحضارة الغربية. ونعتقد أن هذا الشعور يتملك فئة متغربة داخل الأمة، في حين أن هذه الأخيرة تعيش حالة تيئ للانطلاق، ويشهد على ذلك امتداد الصحوة الإسلامية المباركة، التي هي أحد تعبيرات الاعتزاز بالذات والشعور بالتكريم الإلهي، من خلال الانتماء إلى خير أمة أخرجت للناس. غير أن أهم عوامل الإعاقة عن التحضر اليوم ليست في الشعور بالمغلوبية والدونية، بقدر ما تعود إلى الاستبداد والتسلط المعطل لطاقات الإنسان

$$
2 \text { 2 }
$$


والمكبل لكل فلعلية، إن الاستبداد والقهر اللذين لا يقيمان وزناً لكرامة الإنسان وقيمته، هما اللذان يجعلان كتاب قيمة الإنسان استجابة للاجة واقعية وضرورية، حتى يترسخ لدى جميع فئات الأمة تكريم الإنسان كعقيدة إسلامية ثابتة، مَنْ يستهتر بها يعد مستهتراً بعقائد الإسلام، ويصبح الدفاع عنها ومدافعة العدوان عنها كما يقول الشيخ الغنوشي، "واجباً شرعياً في استخدام كل ضروب المقاومة الممكنة، حتى إعلان الجهاد

$$
\text { وطلب الاستشهاد من أجل إقرارها". } 3
$$

خامساً: ذكر المؤلف في بداية الفصل الأول أنه يهدف إلى تتبع مظاهر تكريم الإنسان وذلك بمقتى مطلق الإنسانية فيه، دون اعتبار لما يلحقه من العوارض مثل اللون أو الجنس أو الدين، ثم يذكر بعد ذلك من مظاهر التكريم "طمأنينة الخلود"، حيث خُصّ الإنسان دون سائر الموجودات بحياة أخرى بعد الموت يكون فيها المخلود. وإن انتفاء العدم في حق الإنسان حسب رأي المؤلف، هو في حد ذاته يُعلُّ تكريعاً له، لأن العدم يتضمن النقص. ولكن نحن نتساءل بأي معنى يمكن عدُّ الخلود في النار مثلاً تكريعاًٌ إن الخلود

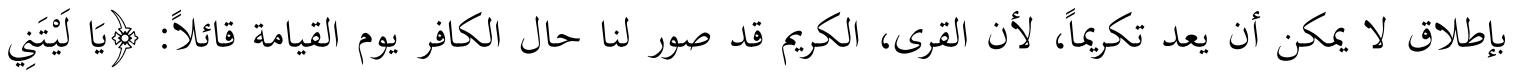
كُنْتُ تُرابابَه. (النبأ:40). فالعدم في حق هؤلاء هو أكرم من الخلود، إذ الخلود لا يعد تكريماً إلا إذا كان في الجنة، ويف هذه الحالة، فإنه ليس تكريماً للإنسان بمقتضى مطلق الإنسانية فيه، وإنما هو متعلق بإحدى

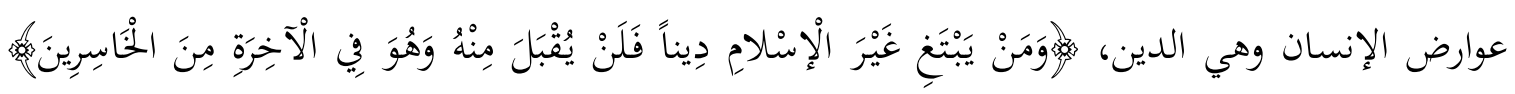
(آل عمران:85). وقد نؤوّل موقف المؤلف على أساس أن الإنسان وبمقتضى مطلق الإنسانية فيه، مرشح للخلود في الجنة، وبالتالي فهو مكرم بانفتاح بجال الخلود أمامه، إذا ما اختار دين الإسلام. ولكن حتى في تهام هذه الحالة فإننا نتساءل عن الفرق بين مظهري التكريم والإهانة، إذا ما علمانا أن الإنسان مرشح وبنفس الدرجة إلى الخنلود في النار، لكون تركيبته لا تجبره على سلوك طريق الجنة، "فقد ركب الإنسان بما يمكنه من اختيار أحد الطريقين والمضي فيه، وهو ما وصفه الله تعالى بقوله:

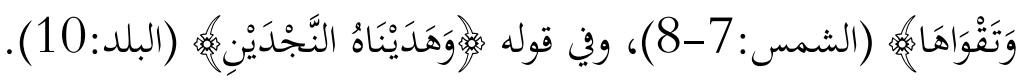


سادساً: إن هذا الكتاب يعد محاولة قيمة لبناء تصور إسلامي لقيمة الإنسان، يتأسس على نصوص الوحي الإلهي، مما يتوجب إقامتها الدفاع عنها، وهو فضلاً عن ذلك يهوز على أهمية كبرى بالنظر إلى

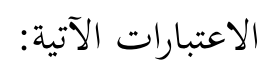

أ- إن كتاب قيمة الإنسان يمثل حلقة متقدمة من سلسلة مشروع "الإنسان في العقيدة الإسلامية". ولقد كان من الممكن أن يكون بمثابة الحلقة الأخيرة في هذه السلسلة، لكونه يمثل أحد أهدافها، وأيضاً لأن مظاهر تكريم الإنسان المذكورة في الكتاب، إنما تتأسس على تصور مبدأ الإنسان "شرفية الخلقق"، ووظيفته "عزة التكليف"، ومصيره "طمأنينة الخلود". وهي التصورات التي سيظل هذا الكتاب بحاجة إليها من أجل استكمال التصور الشامل للإنسان.

ب- يمثل هذا الكتاب أيضاً استجابة ضرورية لواقع المسلمين، الذي يخيم عليه ليل الاستبداد والقهر. وليس من قبيل الصدفة أن يصدر هذا الكتاب في الوقت الذي تُزهق فيه أرواح الكثيرين من أبناء الأمّة داخل

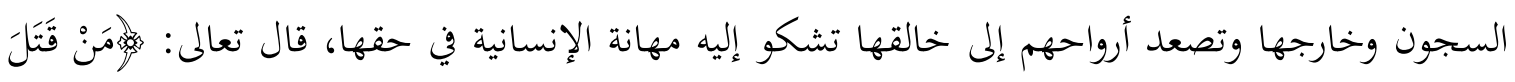

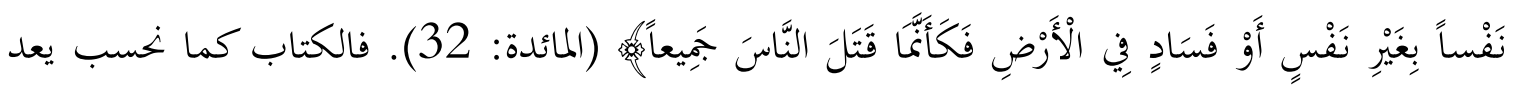
صرخة مدوية لأمة الإسلام، عسى أن تتعبد ربها بتكريم الإنسان، ومدافعة كل عدوان يستهدف قيمته.

ج- إن هذا الكتاب يعد استجابة لحاجة البشرية التي ما زالت تشهد مظاهر الدمار، والحروب التي لا تقيم وزناً لقيمة الإنسان وكرامته، بل إنا اليوم تقف على أبشع مظاهر الاستهتار بقيمة هذا الأخير من خلال محاصرة شعوب بأكملها، وبتويع الأطفال -مثلما يحدث في العراق- على الرغم من صدور الإعلانات الدولية العديدة لحقوق الإنسان. ومردُّ ذلك في اعتقادنا، إلى افتقار هذه الإعلانات إلى الأساس الفلسفي الذي يؤمن بالإنسان قيمة مطلقة، وهي معضلة الفكر الغربي الذي لا يرى في الإنسان سوى لحظة متقدمة في تاريخ تطور المادة. ولذلك نجد انه حتى في اللحظات التي "يقر فيها الغربي للإنسان بحقوق... فهو يكذب، فمن يدعون بالإنسان ليس هوة غير المواطن.... الفرنسي أو الإنجليزي أو الغربي عامة.... وحتى هذا الإنسان المواطن لا يحمل تكريماً في ذاته لأنه إنسان وإنما تكريمه في انتمائه لنسق تاريخي واجتماعي وثقافي ترئي 
معين اسمه الوطن أو الطبقة أو الجنس الأوربي". 4 ونحسب أنه لا وجود لهذه الفلسفة التي تمنح الإنسان قيمة مطلقة، إلا في التصور الإسلامي، الذي يتأسس على نصوص الخالق رب العالمين، الذي يمثل كتاب قيمة الإنسان أحد تعبيراته. 